\title{
Análise espacial dos acidentes de trânsito na capital do estado do Pará-Brasil
}

\author{
Spatial analysis of traffic accidents in the capital of the state of Pará-Brasil \\ Análisis espacial de accidentes de tránsito en la capital del estado de Pará-Brasil
}

Recebido: 25/04/2021 | Revisado: 03/05/2021 | Aceito: 13/07/2021 | Publicado: 17/07/2021

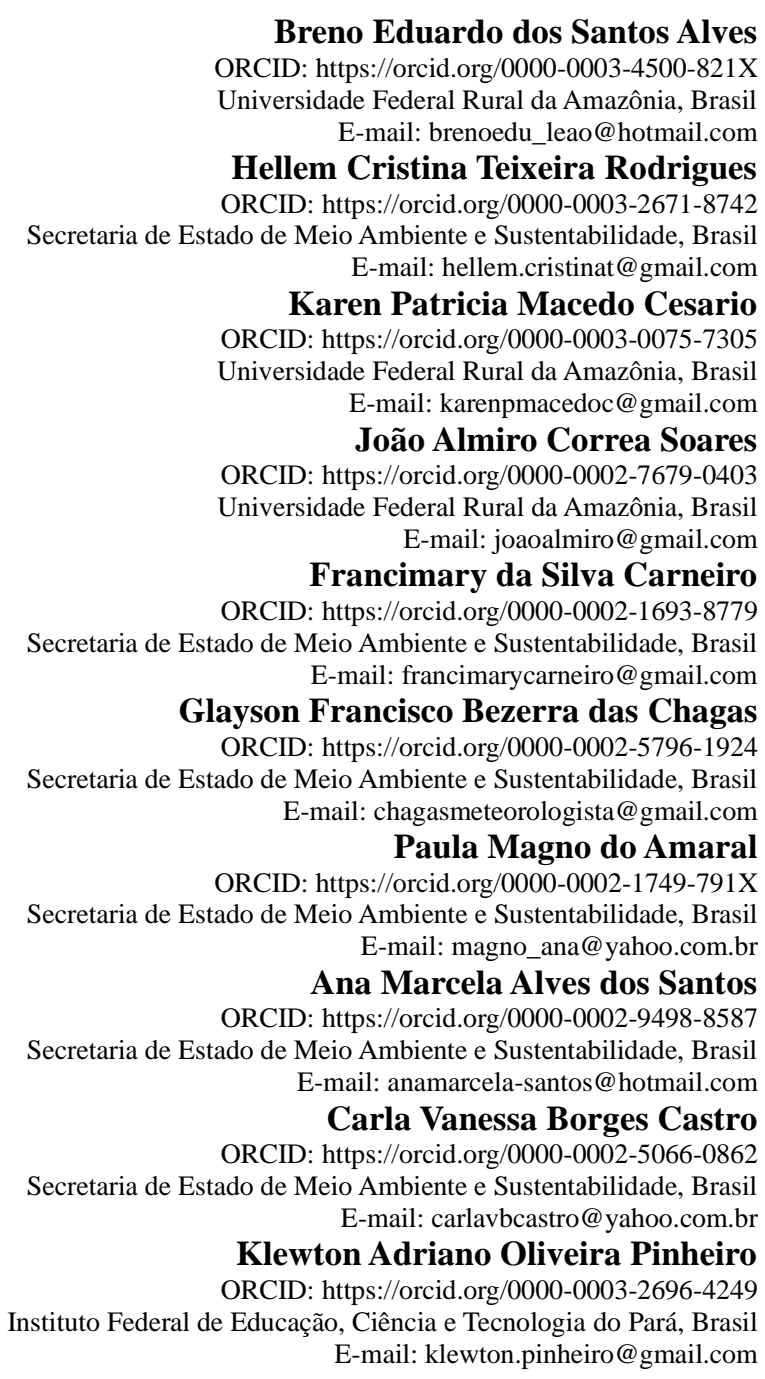

\begin{abstract}
Resumo
O trânsito brasileiro é caótico e possui alta taxa de acidente, influenciada principalmente pelas: 1 - Condições de vias; 2 - Clima e 3 - Crescimento populacional. Existem várias definições de acidentes, dentre elas temos: evento não intencional e evento não premeditado. Sabendo que essa problemática atinge várias capitais do país, Belém foi escolhida por ter grandes problemas em toda sua mobilidade urbana. Sendo assim, o objetivo é analisar estatisticamente as ocorrências espaciais de acidentes de trânsito no ano de 2017, considerando: bairros e ruas; com o intuito de plotar mapas temáticos sobre a respectiva analise. A metodologia empregada foi: 1 - a coleta de dados brutos junto a Superintendência Executiva de Mobilidade Urbana de Belém (SeMOB); 2 - utilização de software Excel para analisar as variáveis e 3 - aplicação no Software ArcGIS 10.1 a fim de plotagem sistemática de mapas temáticos, requerendo resultados consistentes sobre a problemática para fácil entendimento e representação por meio de ilustrações temáticas, informando regiões críticas de ocorrências e as variáveis que mais influenciaram nos dados, assim como discutir os resultados observados com o atual cenário da cidade.
\end{abstract}

Palavras-chave: Áreas críticas; Mapas; Sociedade; Transtornos; Trânsito. 


\begin{abstract}
Brazilian traffic is chaotic and has a high accident rate, mainly influenced by: 1 - Road conditions; 2 - Climate and 3 - Population growth. There are several definitions of accidents, among them we have: unintentional event and unpremeditated event. Knowing that this problem affects several capitals in the country, Belém was chosen for having major problems in all its urban mobility. Therefore, the objective is to statistically analyze the spatial occurrences of traffic accidents in 2017, considering: neighborhoods and streets; in order to plot thematic maps on the respective analysis. The methodology used was: 1 - the collection of raw data with the Executive Superintendence of Urban Mobility of Belém (SeMOB); 2 - use of Excel software to analyze the variables and 3 - application in ArcGIS 10.1 Software in order to systematically plot thematic maps, requiring consistent results on the problem for easy understanding and representation through thematic illustrations, informing critical regions of occurrences and the variables that most influenced the data, as well as discussing the results observed with the current city scenario.
\end{abstract}

Keywords: Critical areas; Maps; Society; Disorders; Traffic.

\title{
Resumen
}

El tráfico brasileño es caótico y tiene una alta tasa de accidentes, principalmente influenciado por: 1 - Las condiciones de la carretera; 2 - Clima y 3 - Crecimiento poblacional. Existen varias definiciones de accidentes, entre ellas tenemos: evento no intencional y evento no premeditado. Sabiendo que este problema afecta a varias capitales del país, Belém fue elegida por tener grandes problemas en toda su movilidad urbana. Por tanto, el objetivo es analizar estadísticamente las ocurrencias espaciales de accidentes de tránsito en 2017, considerando: barrios y calles; con el fin de trazar mapas temáticos en el análisis respectivo. La metodología utilizada fue: 1 - la recolección de datos brutos con la Superintendencia Ejecutiva de Movilidad Urbana de Belém (SeMOB); 2 - uso del software Excel para analizar las variables y 3 - aplicación en el software ArcGIS 10.1 para trazar mapas temáticos sistemáticamente, requiriendo resultados consistentes sobre el problema para su fácil comprensión y representación a través de ilustraciones temáticas, informando regiones críticas de ocurrencias y las variables que la mayoría influyó en los datos, además de discutir los resultados observados con el escenario actual de la ciudad.

Palabras clave: Areas criticas; Mapas; Sociedad; Trastornos; Tráfico.

\section{Introdução}

O estudo sobre a ocorrência espacial dos acidentes de trânsito na cidade de Belém tem grande complexidade, visto que o zoneamento territorial irregular da cidade é um possível fator que influencia a causa de acidentes, assim como as condições das vias, clima local, até mesmo o crescimento populacional no decorrer dos anos é um fator de extrema relevância a ser observado e analisado (Mesquita Filho et al. 2017, Campos et al. 2020), uma vez que reflete em maior consumo da população tanto para bens prioritários como bens supérfluos, como é o caso dos automóveis, contribuindo, assim, para a maior ocorrência de acidentes.

Segundo Andrade et al. (2013), existem várias definições e classificações para acidentes de trânsito, dentre elas temos: evento não intencional, envolvendo pelo menos um veículo motorizado ou não, que circula por uma via para trânsito de veículos; todo evento não premeditado de que resulte dano em veículo ou na sua carga e ou lesões em pessoas e/ou animais, em que pelo menos uma das partes está em movimento nas vias terrestres ou áreas abertas ao público - pode originar-se, terminar ou envolver veículo parcialmente na via pública.

Com a ocorrência de acidentes de trânsito, outro problema é encontrado. Segundo Malta et al. (2016), em 2013, foram registrados, no Sistema de Informação de Mortalidade (SIM), 42.291 óbitos por Acidentes de Transporte Terrestre (ATT), sendo que em 12.040, o meio de transporte da vítima era a motocicleta. Em relação às internações hospitalares por ATT, para o ano de 2013, foram computadas pelo Sistema de Informações Hospitalares (SIH), no Sistema Único de Saúde (SUS), 170.805 internações, representando um gasto de $\mathrm{R} \$ 231.469 .333,13$. Para um sistema em que o governo arca com as contas do setor público, os gastos são muito elevados, de modo que com medidas de educação do trânsito é possível que haja uma diminuição de acidentes e consequentemente os gastos seriam inferiores (Hernández 2012, Malta et al., 2016, Mendonça et al., 2017).

Segundo os estudos realizados por Bacchieri e Barros (2011), a ocorrência de acidentes de trânsito tem um impacto financeiro elevado na economia do local em que ocorreu, dependendo da quantidade de acidentes e da gravidade, visto que são necessários acompanhamentos médicos para os envolvidos em casos graves. Com a metodologia desenvolvida por Rodrigues, 
foi feito um levantamento de dados com o intuito de quantificar o tamanho dos gastos, para isso foi usado o banco de dados do SUS para comparar os orçamentos por atendimento ambulatorial. Constatou-se que houve um aumento de 4,3 vezes comparado ao levantamento de 3 anos atrás (Souza et al. 2008, Bacchieri E Barros, 2011, Souza \& Silva 2017, Sousa et al. 2020).

O caos no trânsito brasileiro e a realidade de Belém do Pará se caracterizam por altas taxas de acidentes de trânsito e são, geralmente, causados pela imprudência dos condutores na cidade e sendo, provavelmente, influenciada pelo clima belenense, em especial pelas constantes chuvas, com alta pluviosidade, em curto período de tempo, contribuindo para alagamentos constantes. Estes fatores prejudicam a circulação dos veículos, impossibilitando até seu transporte em certos trechos, o que causa transtornos aos motoristas.

Com o intuito de alertar a sociedade, órgãos públicos responsáveis pela segurança no trânsito e condutores, a fim de conscientizar e evitar a alta taxa de acidentes de trânsito na capital paraense, este estudo justifica-se em plotar mapas temáticos, informando as principais ruas e bairros com maior ocorrência de acidentes de trânsito no ano de 2017, assim como informar suas consequências às saúdes física e mental, além do custo financeiro tanto individual quanto coletivo, visto que, no Brasil, a sociedade paga, por meio de impostos, o Sistema Único de Saúde- SUS..

\section{Metodologia}

Este trabalho buscou realizar o estudo e mapeamento das ruas e dos bairros com alto índice de acidentes de trânsito. A área de estudo escolhida foi a cidade de Belém (excetuando-se as ilhas), capital do Estado do Pará, localizada na região norte do país, onde o fluxo de veículos é intenso (Figura 1).

Figura 1. Mapa de localização da área de estudo em relação aos limites territoriais.

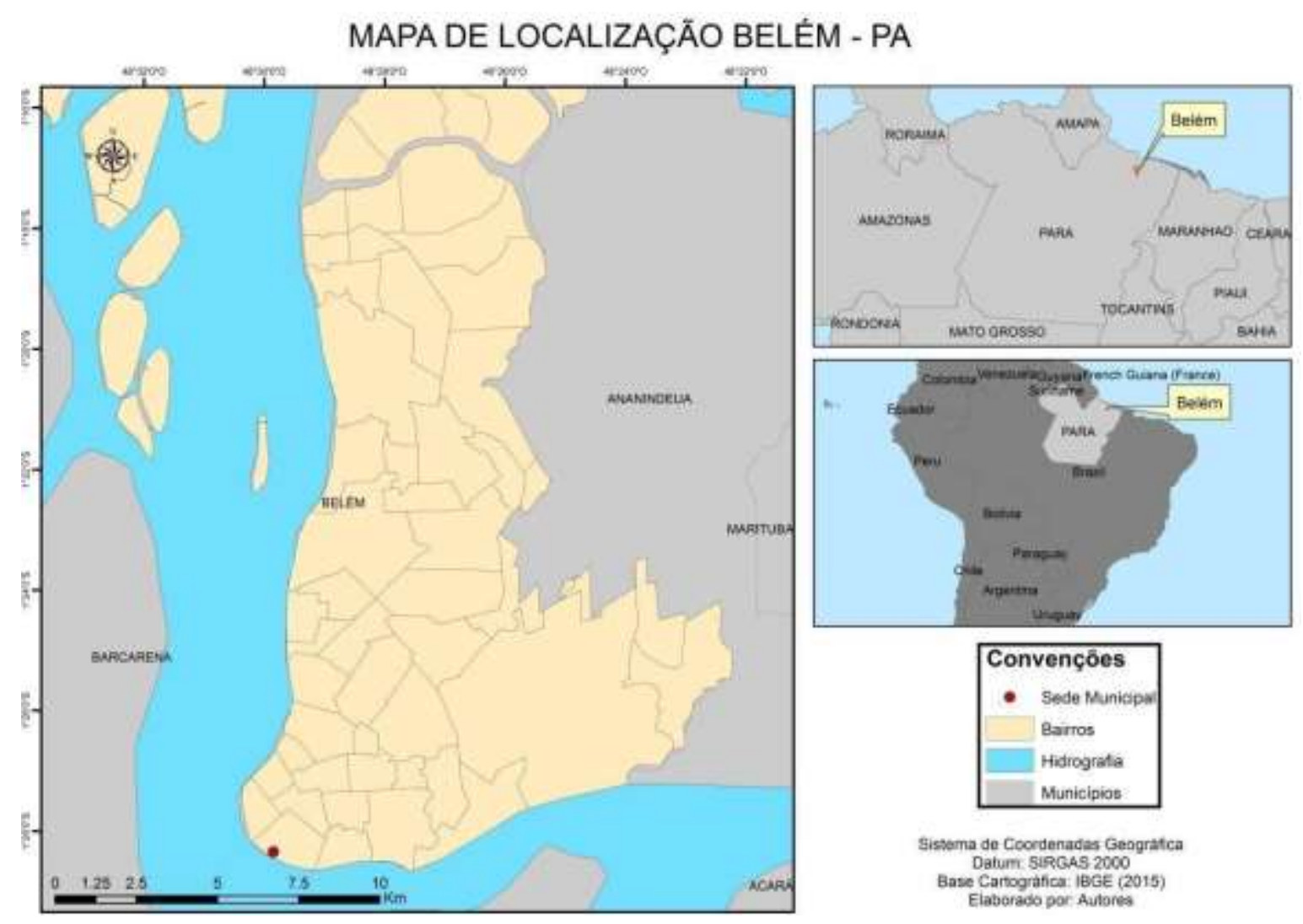

Fonte: Autores. 
O estudo foi desenvolvido por meio de: 1 - Entrevistas com profissionais dos órgãos públicos responsáveis pela fiscalização e monitoramento do trânsito da capital paraense; 2 - Coleta de dados brutos junto a Superintendência Executiva de Mobilidade Urbana de Belém - SeMOB; 3 - Orientação de profissionais da área de geoprocessamento, com o intuito de analisar os dados estatísticos dos acidentes que ocorreram nas vias de Belém no ano de 2017, com a orientação para a confecção dos mapas que fazem a representação dos bairros com maior índice de acidentes de trânsito e a características das ruas.

\section{Entrevistas com responsável}

Nos dias 11 e 15 de dezembro de 2017, foram realizadas as entrevistas com o agente de trânsito da SeMOB Emerson Silva de Sousa, com a aplicação de questionário (Figura 2) com temas considerados pertinentes a pesquisa em questão com a participação de todos os integrantes do grupo.

Figura 2. Questionário aplicado ao agente de trânsito.

\section{QUESTIONÁRIO PARA O PROFISSIONAL DO TRÃNSITO}

1 - Quais as principais causas de acidente?

2 - Quais veículos que mais causa mortes, carro ou moto?

3 - Qual o tempo médio para o órgão competente chegar ao local de acidente e liberar o veículo? E quando tem vítima lesionada?

4 - Existe época ou dia da semana mais propícia a acidentes?

5 - Belém é uma cidade com tempos adversos. Existe um índice maior de acidente em tempo churoso?

6 - Como a lei seca contribuiu para o trânsito de Belém/ o que mudou?

7- As pessoas na área de trânsito veem diferença na condução de veículos entre homens e mulheres?

\section{8 - O uso da tecnologia auxilia o trânsito? Como? Pontos positivos e negativos?}

9 - Existe uma faixa etária de idade que mais inflige às leis de trânsito?

10 - A educação de trânsito é importante para combater a taxa de acidentes?

Fonte: Autores.

\section{Banco de dados SEMOB}

No dia 25 de janeiro de 2018, foi efetuada a visita técnica à SeMOB, onde foi permitido ter acesso às anotações realizadas diariamente por seus agentes de rádio acionados ao ocorrer algum acidente de trânsito nas vias de Belém. A sistematização dos dados é precária, uma vez que é realizado de forma manual por cada agente de plantão, contribuindo para um amontoado de papéis que dificilmente segue uma ordem de organização. Em razão disso, foi registrado fotograficamente cada ocorrência disponível (Figura 3). Vale ressaltar que, para ter acesso aos dados, foi necessário realizar um ofício à SeMOB com certa antecedência, dependendo da liberação desta para executar a visita. 
Figura 3. Dados brutos registrados pelos agentes de rádio da SeMOB.

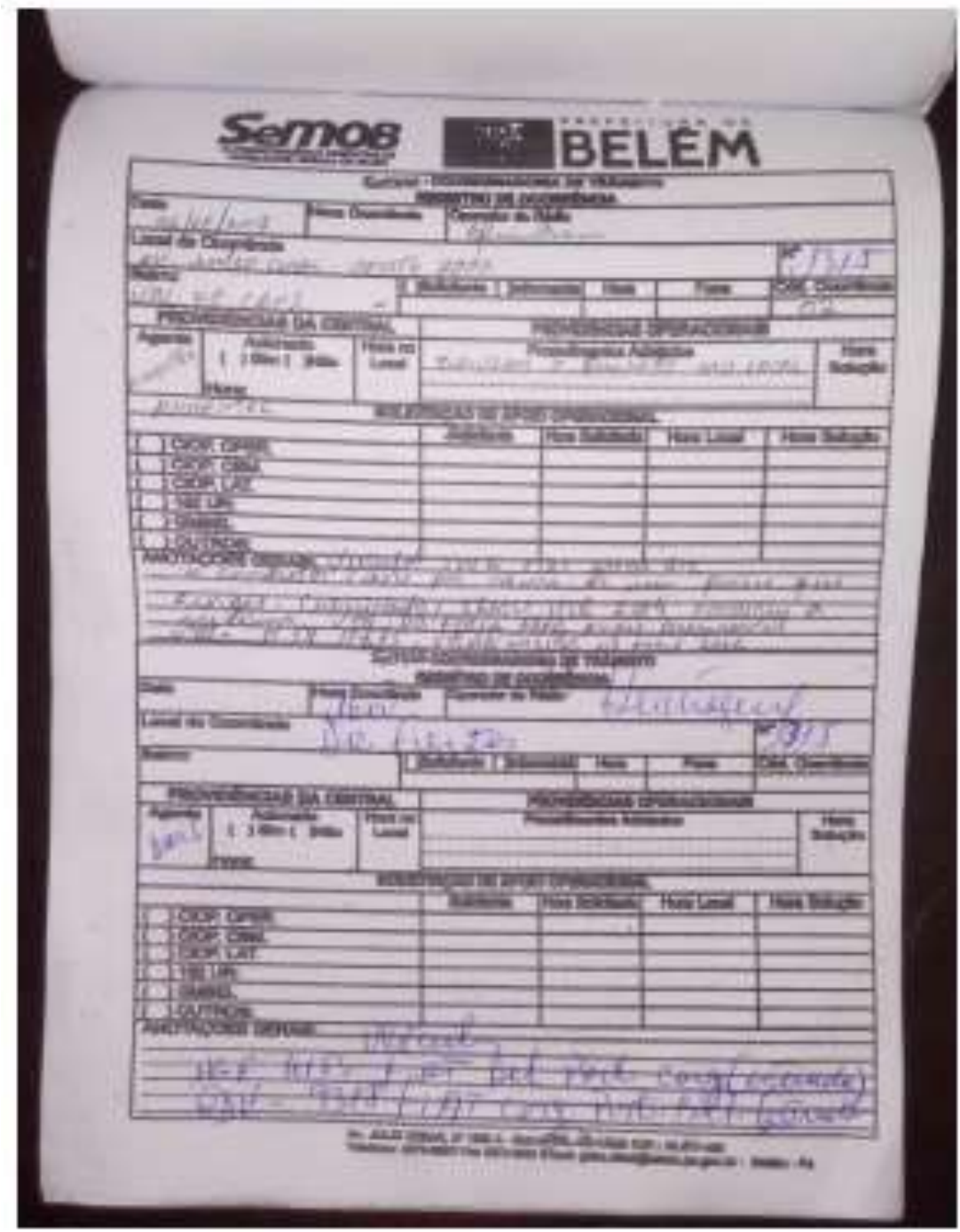

Fonte: Autores.

Em decorrência da falta de sistematização dos dados provenientes da SeMOB, foi preciso realizar a leitura e análise de 521 folhas de ocorrência, de modo a organizar digitalmente todos os registros obtidos do ano em estudo. Como ferramenta de análise, utilizou-se o software Excel, considerando variáveis pré-estabelecidas a serem analisadas, como: bairro, rua e data.

Por conta da divergência entre registros, realizou-se a padronização de dados, juntando as quatro planilhas em uma só, determinando critérios como nome específico para cada rua e bairro, tipos de logradouros e tempos de ocorrência. Por meio de análise estatística, realizou-se a filtragem, no Excel, para a delimitação das áreas com maior quantidade de registros, assim como o mês de maior índice.

Para a produção de mapas temáticos foi utilizando o software ArcGIS 10.1, foram introduzidos os shapefile1 advindos do IBGE como: limites estaduais, municipais, localização de sede e outros, assim como as informações tabeladas na base da SeMOB. Para a análise espacial de risco plotou-se os mapas comunicativos, com informações detalhadas sobre ruas, bairros e os perímetros com maior incidência de acidentes de trânsito no ano de 2017, assim como o mês com maior quantidade de registros. 


\section{Resultados e Discussão}

Foi identificado um total de 888 acidentes de trânsito registrados pela SeMOB no ano de 2017. É fundamental comentar que alguns acidentes registrados, como em Mosqueiro, não foram considerados para este trabalho, pois estão fora da área de estudo, a qual foi delimitada para bairros de Belém. Na análise estatística, foi identificado o número de acidentes registrados pelos agentes por cada bairro no ano de 2017. Dentre eles foram destacados os 10 bairros com os maiores índices de acidentes, como mostra a Figura 4.

Figura 4. Gráfico com os 10 bairros de Belém com o maior índice de ocorrência de acidentes de trânsito no ano de 2017.

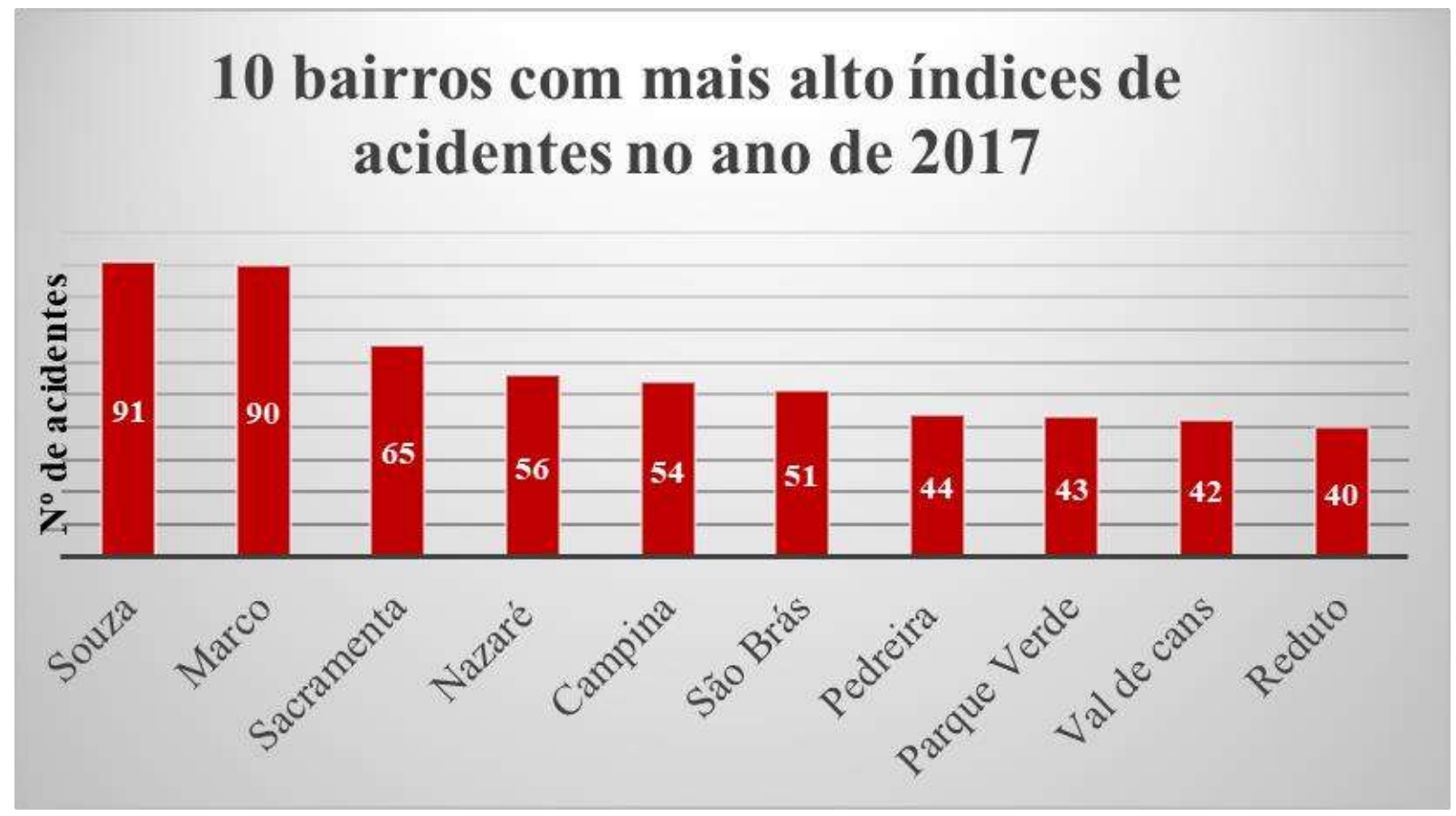

Fonte: Autores.

Analisando os 10 bairros de maior ocorrência de acidentes de forma quantitativa (Figura 4), tem-se um destaque para os bairros do Souza e Marco que englobam parte do corredor troncal (Av. Almirante Barroso) - corredor este que integra quase que exclusivamente Belém a sua região metropolitana, ou seja, as cidades vizinhas (Soares, 2017). Subentendendo que, quanto maior a circulação de veículos em determinado perímetro, maior a ocorrência de acidentes, como demonstra a Figura 5. 
Figura 5. Mapa temático coroplético da ocorrência de acidentes de trânsito por bairro em Belém.
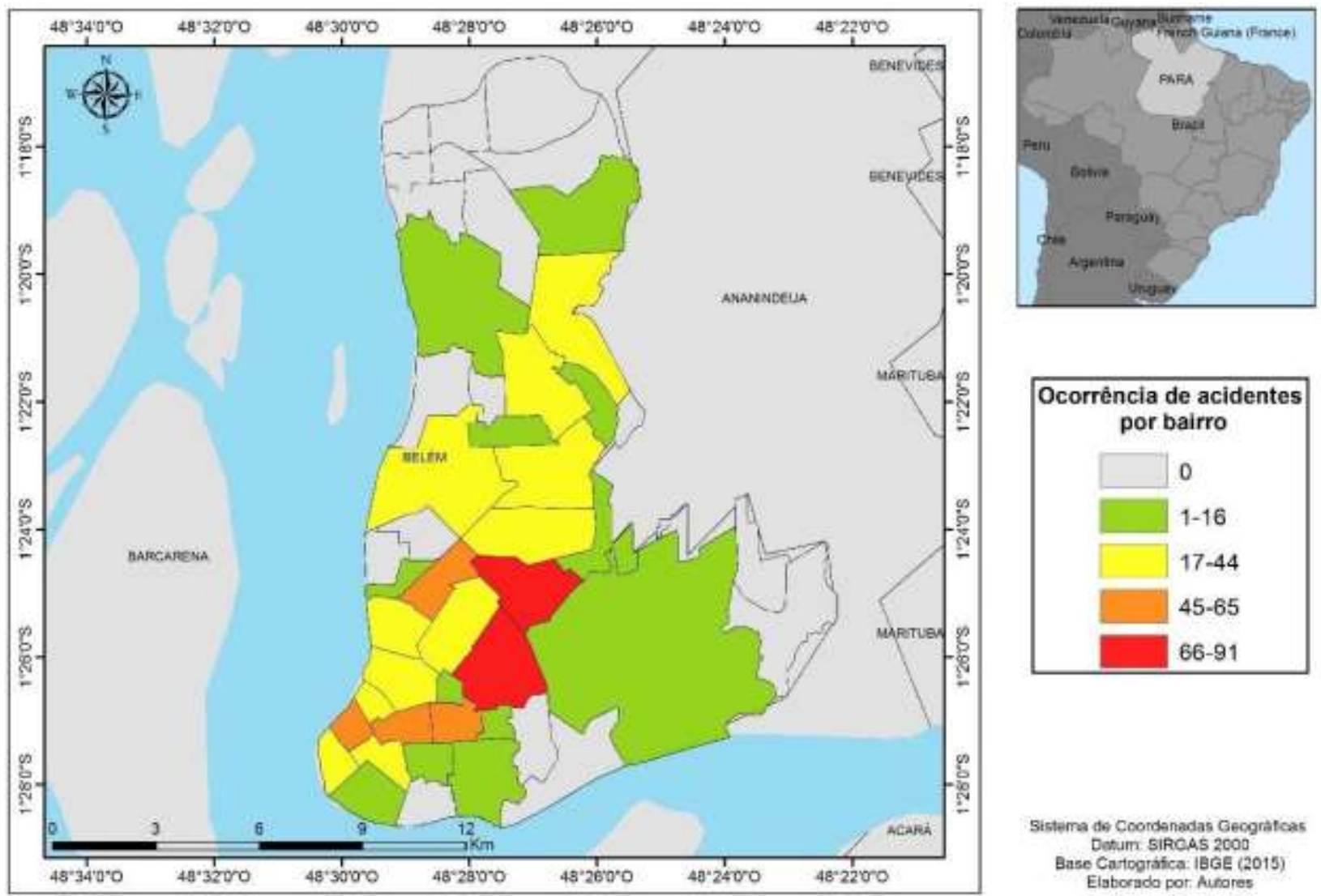
por bairro

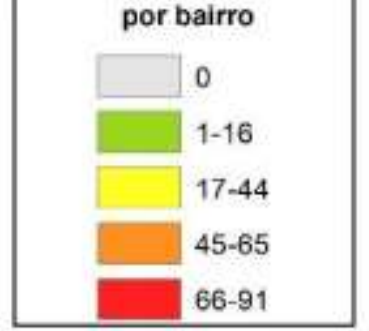

Fonte: Autores.

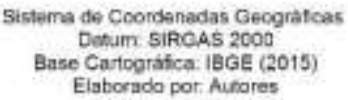

Examinando os três bairros com maiores registros, observa-se que estão interligados pelas vias com maiores ocorrências (Figura 6), como a Av. Almirante Barroso, Av. Júlio César e Av. Pedro Álvares Cabral, podendo ser caracterizadas vias de fluxo constante dentro da capital paraense, sendo um sistema similar ao do corredor troncal, visto que a Av. Almirante é a principal entrada e saída da cidade (Soares, 2017), tem-se também a Av. Pedro Álvares Cabral como uma segunda opção de entrada a cidade e a Av. Júlio César - uma interseção entre as duas ruas anteriormente citadas, possibilitando a entrada e a saída facilitada da cidade. 
Figura 6. Representação de vias com maior ocorrência de acidentes de trânsito registrados pela SEMOB.

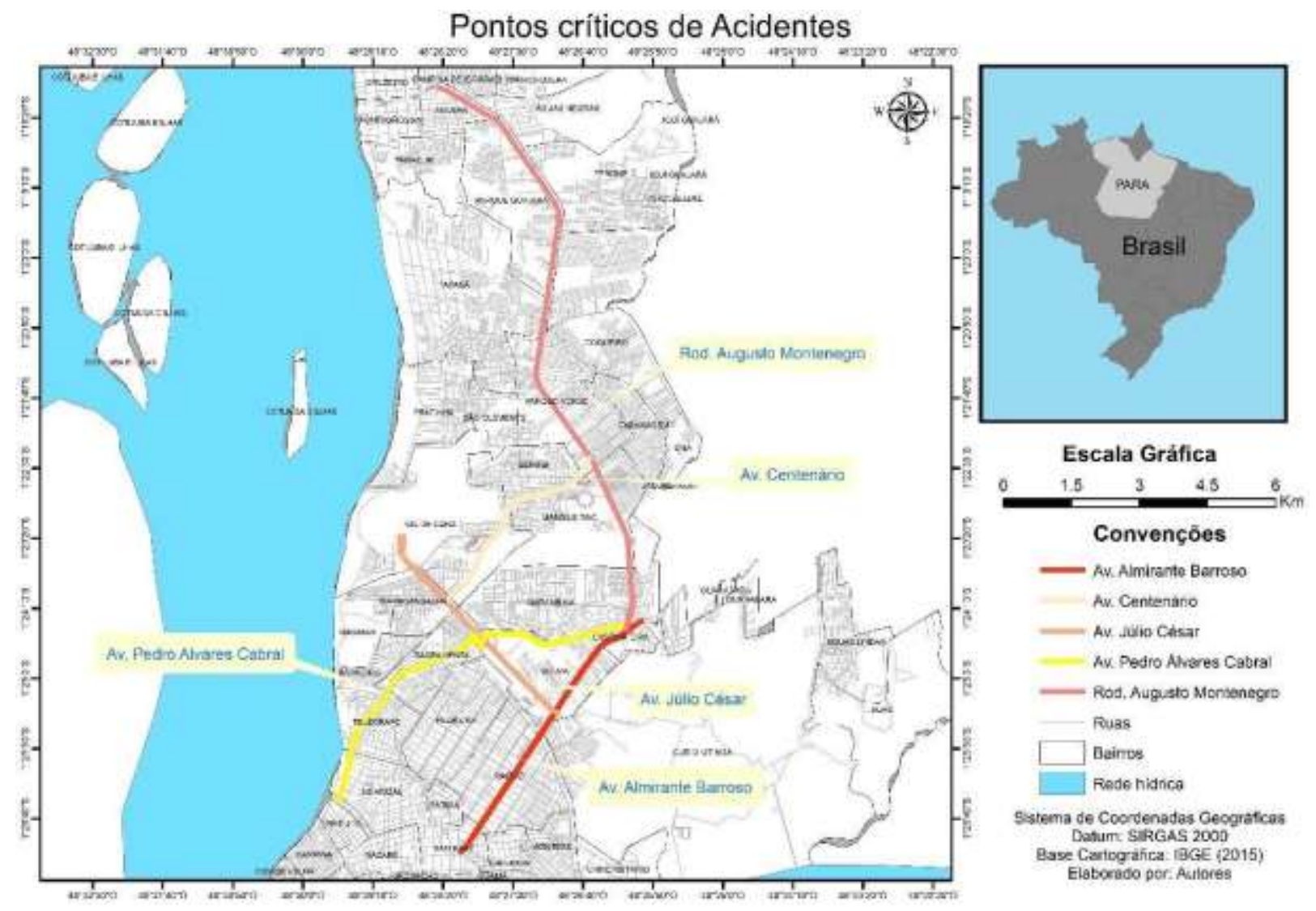

Fonte: Autores.

É importante ressaltar a Rodovia Augusto Montenegro, segunda via com maior índice de acidentes no ano de 2017. Esta via percorre alguns bairros de Belém, como: Icoaraci; Coqueiro; Marambaia; Mangueirão e Parque verde, bairros que estão entre os dez com maiores incidência de acidentes (Figura 7). 
Figura 7. Gráfico da quantidade de acidentes por mês nos bairros de Belém durante o ano de 2017.

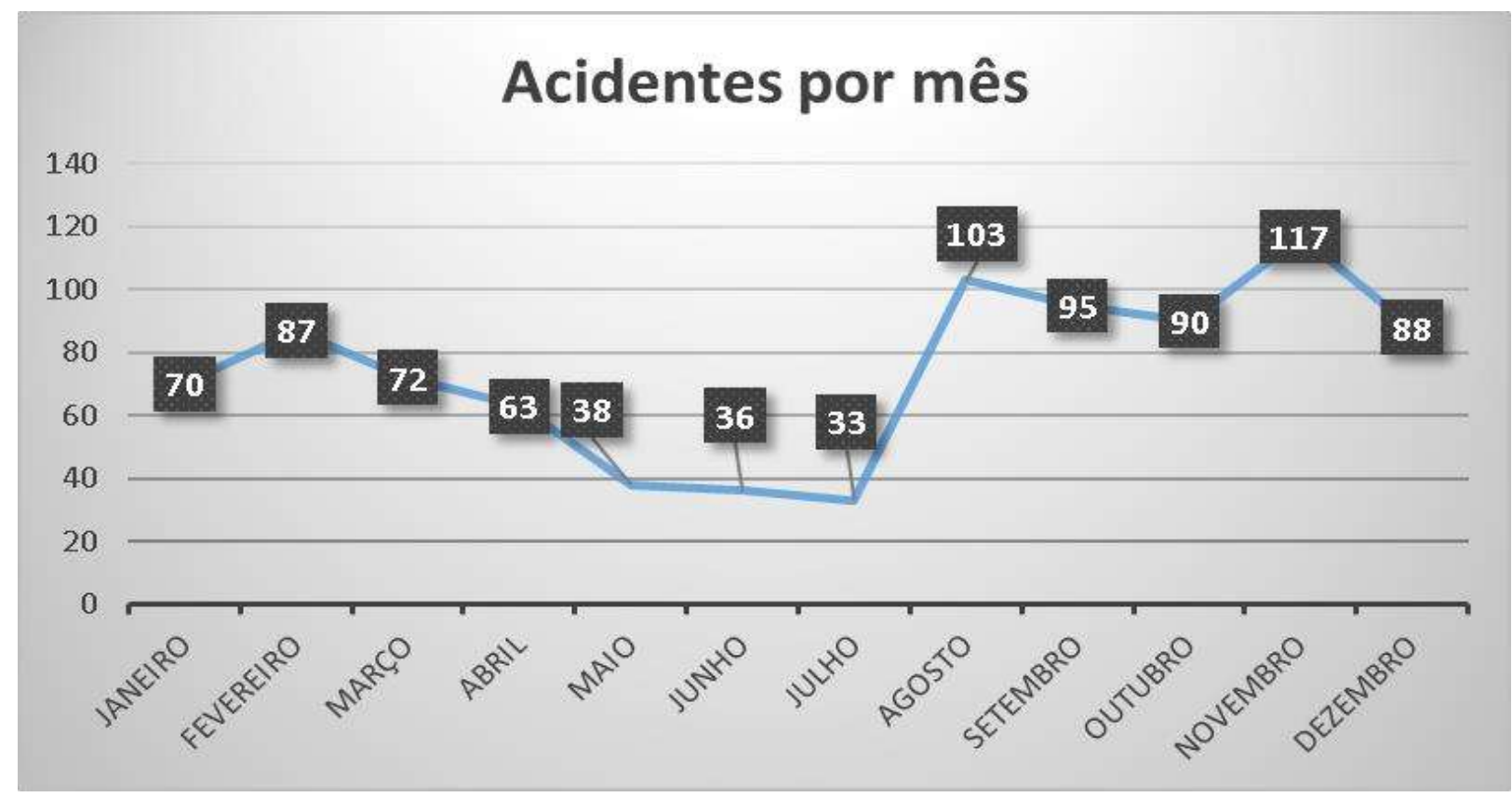

Fonte: Autores.

Destacando também a Avenida Centenário, quinta via com maior índice de acidentes, que liga Av. Júlio César com a Rod. Augusto Montenegro, seu prolongamento dá início a avenida Independência que liga Belém e Ananindeua (Figura 8), sendo assim uma outra forma de saída e entrada à cidade como discorre Soares (2017) em sua pesquisa também. Uma observação relevante também seriam as condições de vias como sugere Mesquita Filho et al. (2017), as obras governamentais que estão sendo feitas em algumas dessas vias como a Av. Almirante Barroso e Rod. Augusto Montenegro. Sendo elas interligadas com praticamente todas essas vias de alto índice de acidente, vê-se que o trânsito é caótico que por consequência acaba corroborando com os acidentes de trânsito. É importante ressaltar que, a soma de todos os acidentes que ocorrerem nas vias citadas acima foi de 358, ou seja, $40 \%$ do total de acidentes registrados no ano de 2017 . Uma porcentagem consideravelmente alta. 
Figura 8. Vias com maiores índices de acidentes no ano de 2017.

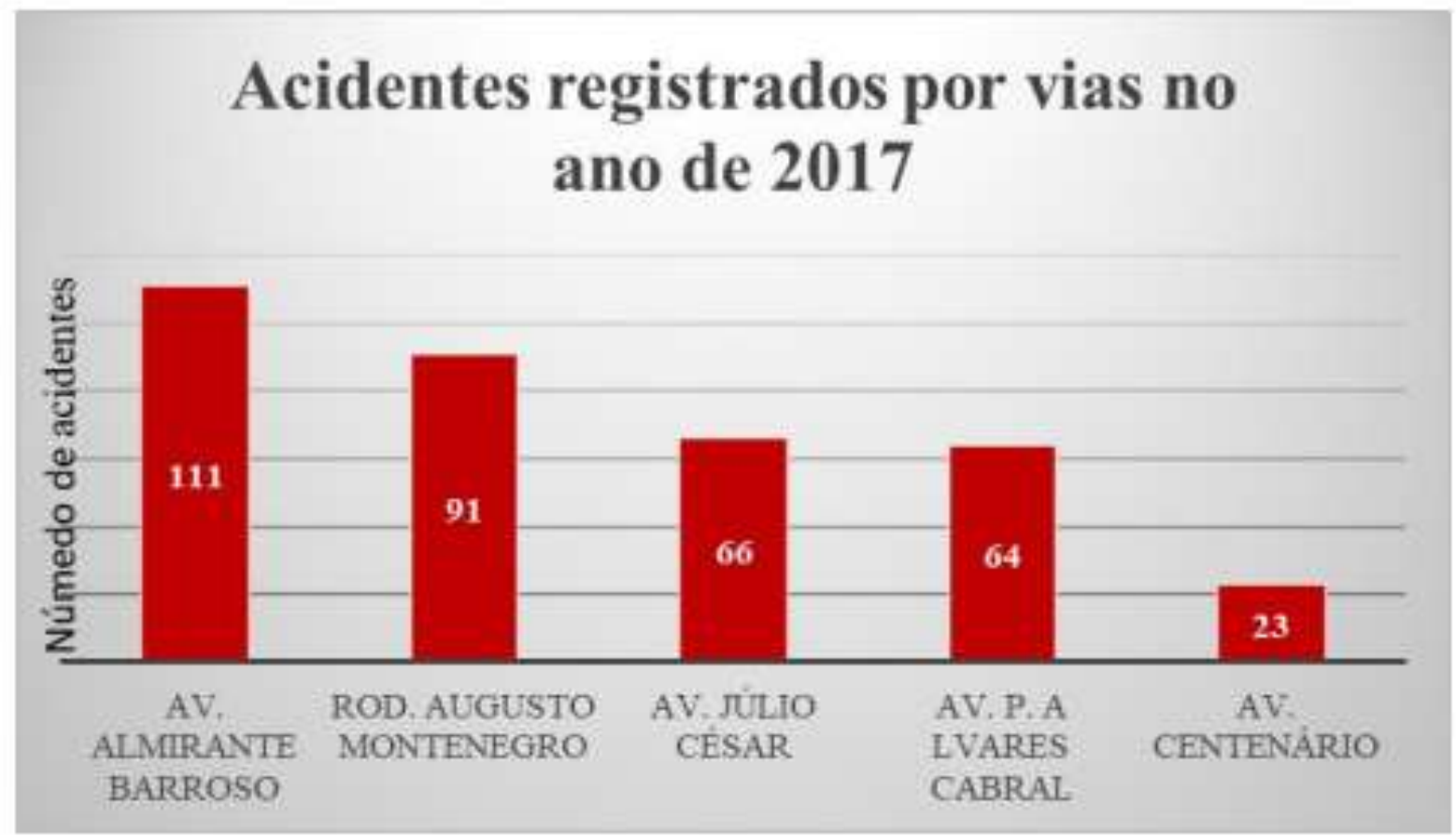

Fonte: Autores.

Outro fator a se estudar foi a ocorrência por período de tempo, ou seja, índices de acidentes mensais, onde foi possível observar que, de janeiro a julho, os índices de acidentes foram menores que o restante dos meses de 2017. Neste período, o maior índice de acidentes foi em fevereiro, mês com altos índices pluviométricos (Figura 9) e período festivo, e o menor no mês de julho, mês de férias escolares, o que faz com que o fluxo de veículos e pessoas seja menos intenso na cidade.

Já o período de agosto a dezembro, observou-se os maiores registros de acidentes, podendo estar atrelados ao retorno das férias escolares no mês de agosto e nos demais meses por conta dos períodos comemorativos da cidade, como o círio de Nazaré e o Natal, épocas nas quais a cidade recebe um grande número de pessoas. 
Figura 9. Índice pluviométrico dos meses de 2017.

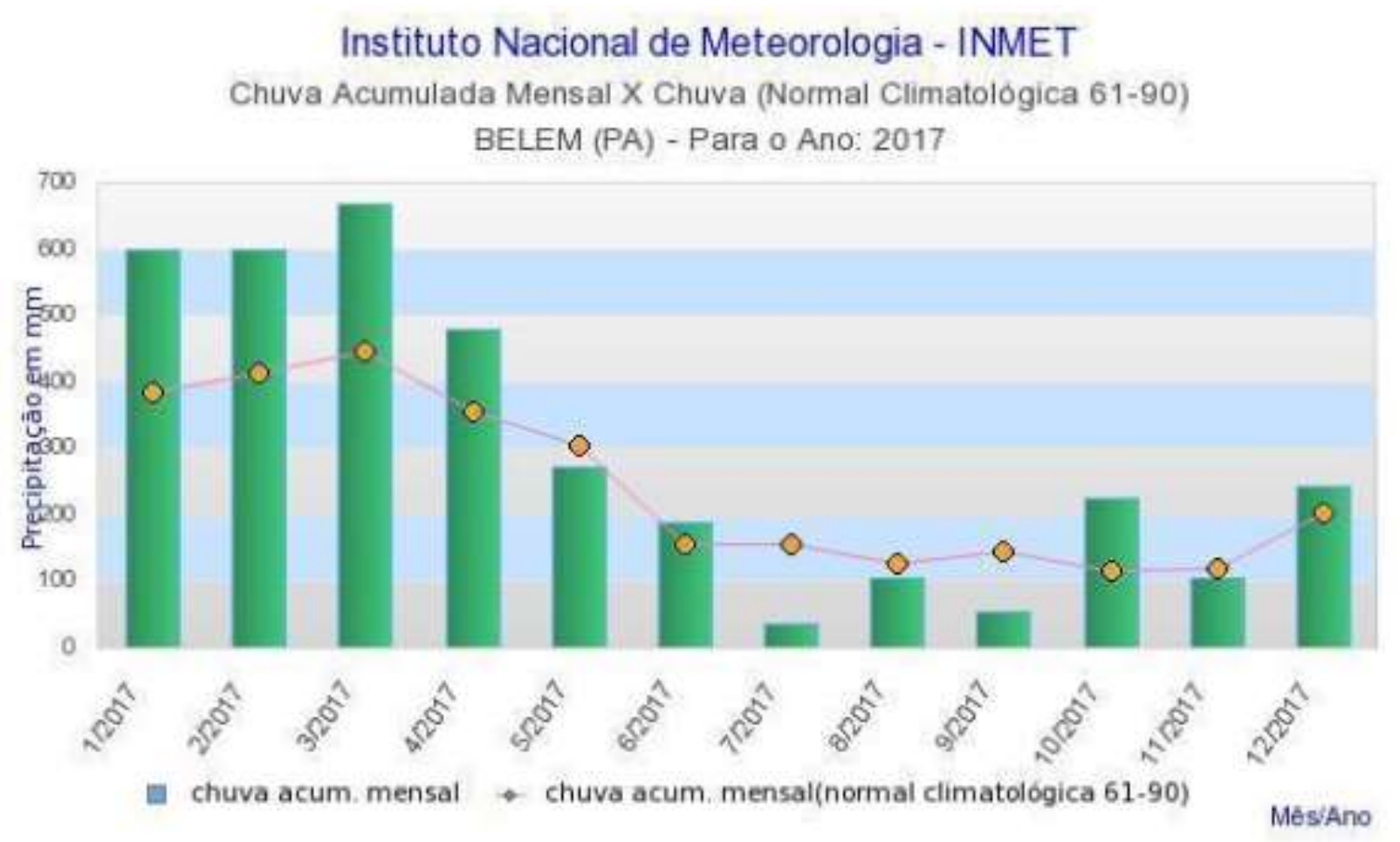

Fonte: INMET (2018).

Em entrevista com o agente da SeMOB, foi constatado que as principais causas de acidentes são "o uso do aparelho celular e a pressa dos condutores para chegarem ao seu destino", caracterizando a imprudência no trânsito. Na entrevista, foi relatado que os veículos que mais se envolvem em acidentes são as motos, e que as mulheres são mais prudentes que os homens no trânsito. Durante o encontro, o agente foi indagado sobre o período chuvoso ter interferência na ocorrência de acidentes e este discorreu que sim. No decorrer do trabalho, pode- se verificar que o fator clima é contribuinte para o aumento dos registros, mas vale ressaltar que não é o único, tendo em vista a complexidade da ocorrência de um acidente de trânsito.

Em análise quantitativa dos acidentes, pode-se perceber o índice elevado, sendo mais de 2 acidentes registrados por dia, fora os acidentes que ocorrem diariamente e são resolvidos de forma amigável ou não são registrados. Essa relação gera uma série de transtornos para a sociedade, como os custos físicos e psicológicos dos acidentes como cita Malta et al. (2016), uma vez que, dificilmente, na eventualidade do acidente, ninguém saia ferido ou traumatizado, assim como mostra Bacchieri e Barros (2011), dado que, para cada registro da SeMOB, a média de carros envolvidos em cada acidente é dois, caracterizando, no mínimo, duas pessoas que deverão passar por cuidados médicos, gerando despesas próprias ou para a sociedade, dado que todo cidadão brasileiro sustenta o SUS.

Realizando a avaliação das avenidas com maiores ocorrências, foi possível destacar áreas críticas (Figura 10) nas interseções entre as principais vias de mobilidade urbana da cidade, visto que os fluxos constantes e a pressa para chegar ao destino influenciam na maior recorrência de acidentes, por isso delimitou-se o trecho com grandes incidências encontradas neste estudo. 
Figura 10. Mapa temático representando as interseções mais representativas de acidentes de trânsito no ano de 2017.

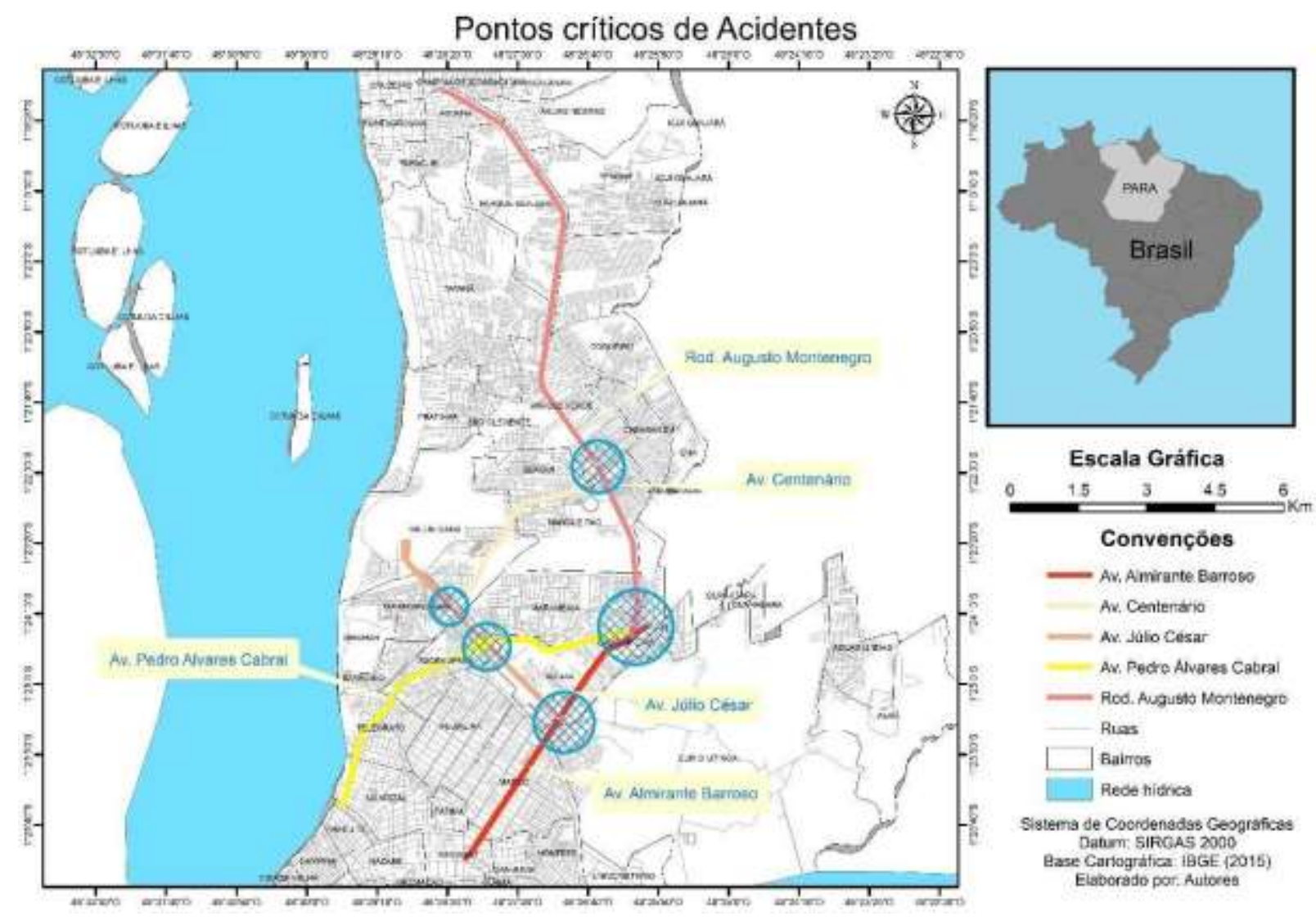

Fonte: Autores.

\section{Considerações Finais}

Dentro do contexto demonstrado, considera-se que:

A Superintendência Executiva de Mobilidade Urbana de Belém deverá se adaptar ao cenário atual e sistematizar suas informações, visando estabelecer perímetros críticos de acordo com os registros que recebe dos agentes de rádio, para fiscalizar os pontos de maior incidência, assim como reforçar as campanhas de conscientização.

O planejamento da mobilidade urbana deixa a desejar, pois as avenidas que mais apresentam ocorrências são as mesmas que apresentam o maior fluxo de veículos diariamente.

Tem-se o fator clima, o qual dificulta o trafegar, pois é recorrente as altas taxas pluviométricas na região, contribuindo no comprometimento da circulação nas vias de rolamento com segurança.

As obras que estão em execução nas vias das cidade (Obras BRT) contribuem para as ocorrências de acidentes.

Considerar a continuidade desse estudo, utilizando outras fontes de informações base, como o Departamento de Trânsito do Estado do Pará - DETRAN.

\section{Referências}

Andrade, C. A., Lopes, I., Felix, M. K. R. \& Fonseca, W. (2013). Identificação de segmentos críticos em acidentes de trânsito na Rodovia DF-002: Geoprocessamento de dados do Instituto de Criminalística da Polícia Civil do Distrito Federal. Revista Brasileira de Criminalística. 10.15260/rbc.v2i1.28.

Andrade, P. H. M., et al (2021). A relação entre o uso de álcool e acidentes de trânsito em Caxias - MA. Research, Society and Development, 10, e54410817731. 10.33448/rsd-v10i8.17731.

Bacchieri, G., \& Barros, A. J. D. (2011). Acidentes de trânsito no Brasil de 1998 a 2010 : muitas mudanças e poucos resultados. https://pesquisa.bvsalud.org/portal/resource/pt/lil-601142. 
Campos, J. M. P., Silveira, E. F., \& Périco, E. (2020). Cidades seguras e resilientes? Das metas de desenvolvimento sustentável à mortalidade evitável em pequenos municípios. Revista Ibero Americana de Ciências Ambientais, 11, 274-283. http://doi.org/10.6008/CBPC2179-6858.2020.006.0023.

Dantas, A. A. N., Fraga, Y. S. B., Santos, F. B. C., \& Pignata, G. S. (2021). Influência da duplicação da BR-020 no número de acidentes de trânsito entre Planaltina/DF e Formosa/GO. Research, Society and Development, 10, e25010615636. 10.33448/rsd-v10i6.15636.

Hernández H. V. (2012). Análisis exploratorio espacial de los accidentes de tránsito en Ciudad Juárez, México. Revista Panamericana de Salud Pública. 31(5): 396-402. https://www.scielosp.org/pdf/rpsp/2012.v31n5/396-402/es.

Hogan, D. J. (1993). Crescimento populacional e desenvolvimento sustentável. Lua Nova: Revista de Cultura e Política. 31, 57-78. https://doi.org/10.1590/S0102-64451993000300004.

Instituto Nacional De Meteorologia-INMET. Endereço: http://www.inmet.gov.br/portal/.

Malta, D. C, Mascarenhas, M. D. M., Bernal, R. T. I., Silva, M. M. A, Pereira, C. A., Minayo, M. C. S., Morais Neto, O. L. (2008). Análise das ocorrências das lesões no trânsito e fatores relacionados segundo resultados da Pesquisa Nacional por Amostra de Domicílios (PNAD) - Brasil. Ciência \& Saúde Coletiva. 2011;16(9): 3679-87. https://doi.org/10.1590/ S1413-81232011001000005

Malta, D. C., Andrade, S. S. C.A., Gomes, N., Silva, M. M. A., Morais Neto, O. L., Reis, A. A. C. \& Nardi, A. C. F. (2016). Injuries from traffic accidents and use of protection equipment in the Brazilian population, according to a population-based study/Lesões no trânsito e uso de equipamento de proteção na população brasileira, segundo estudo de base populacional. Ciência \& Saúde Coletiva, p399. https://doi.org/10.1590/1413-81232015212.23742015.

Mendonça, M. F. S., Silva, A. P. S. C., Castro, C. C. L. (2017). Análise espacial dos acidentes de trânsito urbano atendidos pelo Serviço de Atendimento Móvel de Urgência: um recorte no espaço e no tempo. Revista Brasileira Epidemiologia. 20(4): 727-741. 10.1590/1980-5497201700040014.

Mesquita Filho, M., Carvalho, C. R. \& Garcia, E. P. (2017). Fatores associados a ocorrência de acidentes de trânsito entre universitários. Ciência \& Saúde, 10(2) 62-70. https://doi.org/10.15448/1983-652X.2017.2.24205.

Miranda, R. B., Souza, J. S., Santos, F. O., Santos, A. S., Fonsêca, C. P., Ferreira, L. N., Rios, P. A. A., \& Cardoso, J. P. (2021). Fatores associados a acidentes de trânsito entre universitários. Research, Society and Development, 10, e26210111668. 10.33448/rsd-v10i1.11668.

Soares, L. R. S. A. (2017). Dispersão metropolitana e seus efeitos sobre a mobilidade urbana nos principais corredores viários da região metropolitana de Belém-PA. Dissrtação apresentada a Universidade Federal do Pará. http://www.ppgeo.propesp.ufpa.br/ARQUIVOS/dissertacoes/2015/D ISSERTA\%C3\%87\%C3\%8 30\%20LUC\%C3\%89LIA\%20DOS\%20REIS.pdf.

Sousa, P. G., Nogueira, T. A., Meza, R. O., Oliveira, V. A. De, Abreu, M. H. T. (2020). Análise espacial das vítimas fatais de acidentes de trânsito por motocicletas em Teresina - Piauí. Research, Society and Development, 9, e9549109506. 10.33448/rsd-v9i10.9506.

Souza, B. de F., \& Silva, J. P. (2017). Análise Espacial dos acidentes de trânsito em Passos (MG). Ciência ET Praxis, 10(19), 31-38. https://revista.uemg.br/index.php/praxys/article/view/2639.

Souza, V. R., Cavenaghy, S., Alves, J. E. D. \& Magalhães, M. A. F. M. (2008). Análise espacial dos acidentes de trânsito com vítimas fatais: comparação entre o local de residência e de ocorrência do acidente no Rio de Janeiro. Revista Brasileira de Estudos de População 25. https://doi.org/10.1590/S010230982008000200010 .

Superintendência Executiva De Mobilidade Urbana De Belém - SeMOB. 